4.5 Other applications 



\title{
3D finite element seismic analyses of bridges and dams
}

\author{
A. Mellal, S. Commend \& F. Geiser \\ GeoMod consulting engineers, Lausanne, Switzerland
}

\begin{abstract}
In recent years, the seismic verification of structures according to European construction norms has dramatically evolved. On the one hand, pseudo-static replacement forces based on design spectra have been widely used in the past decades, providing a simple method to evaluate the safety of buildings and bridges. However this method can be too conservative and lead to costly reinforcement of existing structures. On the other-hand, displacement-based methods taking into account the material nonlinearity of structures, also known as push-over analyses, provide an alternative to force-based methods, and usually reproduce better the real behavior of a structure submitted to earthquake-like loading, without overestimating the resulting displacements and stresses. Finally, nowadays, the increase of computer performance allows us also to run linear or nonlinear time history analyses of structures submitted to real accelerograms, with or without soil-structure interaction. In this paper we propose to highlight advantages and limitations of the three aforementioned methods, with the help of linear and nonlinear 3D finite element models, applied to case studies, i.e. the seismic verification of a highway bridge, and the dynamic analysis of an arch dam in the Alps.
\end{abstract}

\section{INTRODUCTION}

\subsection{Brief review of the seismic design methods}

In this paragraph, an overview of four methods used to assess the seismic behavior of structures is conducted. Figure 1 classifies these methods with respect to the considered behavior of the structure, and the nature of the sollicitation.

\subsubsection{Replacement forces method $(R F)$}

An equivalent lateral horizontal load (Eq. 1) is applied to the structure. Usually, boundary conditions are fixed at the foundations. The replacement force is proportional to the sum of the mass of the structure $\mathrm{m}_{\text {tot }}$ and the permanent loading $\mathrm{q}_{\mathrm{perm}}$. Figure 2 illustrates the elastic response spectra given in the Swiss norms (SIA $2612003)$ to evaluate the amplitude of the replacement force as a function of fundamental period of the

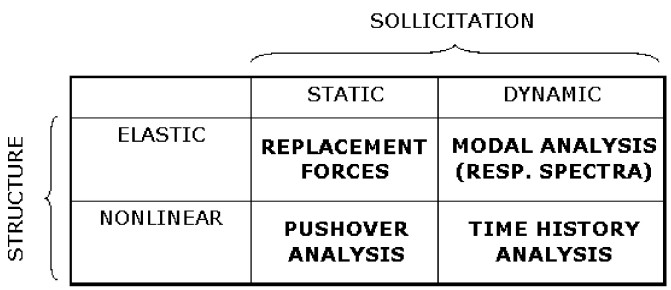

Figure 1. Analysis methods. structure $T_{1}$, structure type, soil's nature and seismicity of the considered zone.

$F=S_{d} \sum\left(m_{t o t}, q_{\text {perm }}\right)$

The advantages and drawbacks of the method are: on the one hand, it is a simple, fast, linear method, cited by all design norms worldwide, and on the other hand, this method is far from being able to predict the real seismic behavior of the structure, and simplifying hypotheses linked with the absence of nonlinear behavior often yield to an overestimation of the resulting displacements and stresses.

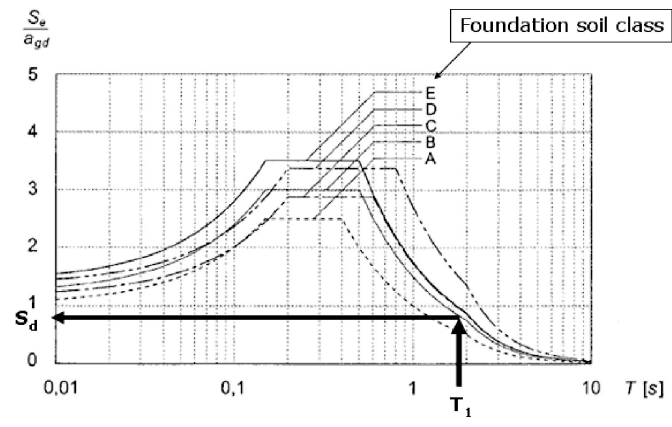

Figure 2. Determination of the lateral replacement force amplitude. 


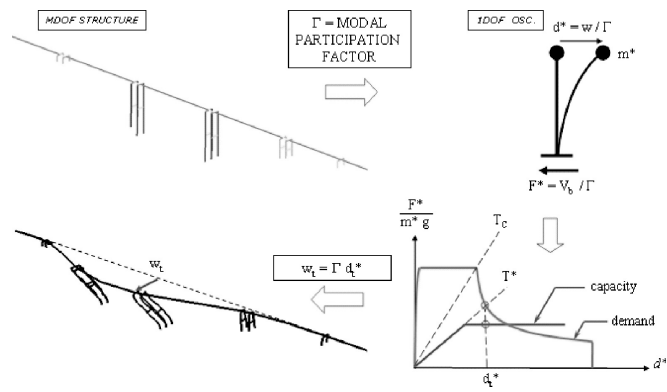

Figure 3. Pushover analysis summary.

\subsubsection{Modal analysis (response spectrum method)}

In modal analysis the structure is decomposed into a sum of simple 1DOF oscillators. The maximal response of each oscillator with respect to the response spectrum is then computed, and the total maximal response is obtained by superposing the modal responses.

Typically, the seismic assesment of structures with this more elaborated method can gain 10 to $30 \%$ with respect to the replacement forces method. However, it is only valid for linear systems, and thus of limited interest. It won't be investigated further in this paper.

\subsubsection{Nonlinear pushover analysis $(P O)$}

This deformation-based method compares the earthquake's action (target displacement $\mathrm{w}_{\mathrm{t}}$, see Figure 3 ) to the deformation capacity of the structure. This approach is recommended by current design codes (Eurocode 8 2003, SIA 2018 2004).

Two lateral load distributions (unitary and modal, both proportionnal to the total mass) are imposed to the structure in its principal directions (usually longitudinal and transversal). These horizontal forces are increased gradually, and one looks at the evolution of the total shear force $\mathrm{V}$ in the considered direction with respect to a reference node displacement $\mathrm{w}$ (top-floor displacement for a building, maximal deck displacement for a bridge): $\mathrm{V}=\mathrm{f}(\mathrm{w})$. A capacity curve is then obtained by linearizing this curve in an equivalent 1DOF system: $F^{*}=f\left(d^{*}\right)$ (see Fig. 3).

The linear acceleration-displacement demand spectrum is then used to define the target displacement, by comparing the capacity and demand spectra. This operation is not straightforward, a detailed description of the procedure can be found in (Belgasmia et al. 2006).

The deformation capacity of each structural element can be obtained through a nonlinear moment-curvature analysis.

Pushover analyses are most commonly solved with the help of nonlinear finite element codes (here Z_Soil v7 2007). They are usually applied to structural elements only, with fixed or flexible boundary conditions applied to their foundations. The advantage of this static, yet nonlinear method on the two first presented approaches is straightforward: elastoplasticity is introduced explicitly in the FE model, yielding a better understanding of the structure's real behavior under seismic loading. The fact that this method does not compute displacements and stresses time histories can be seen either as a drawback (lack of information with respect to real dynamic time history analyses) or as an advantage (no need for accelerograms as seismic input, gain of computational time).

\subsubsection{Dynamic time history analysis $(\mathrm{TH})$}

The first three methods described here focus on structural engineering, where the soil is only taken into account through the nature of boundary conditions at the structure's foundation. In order to solve soilstructure interaction with the help of a finite element program, one must write the discrete equilibrium equations of motion (Eq. 2).

$\mathbf{M} \ddot{\mathbf{u}}+\mathbf{C} \dot{\mathbf{u}}+\mathbf{F}(\mathbf{u})=\mathbf{Q}(t)$

In Equation 2, $\mathbf{u}, \dot{\mathbf{u}}$ and $\ddot{\mathbf{u}}$ are respectively the unknown relative displacements, velocities and accelerations vectors, with respect to the model's base. $\mathbf{M}$ is the mass matrix of the soil-structure system, $\mathbf{C}$ the damping matrix and the nonlinear term $\mathbf{F}(\mathbf{u})$ reduces to $\mathbf{K u}$ - where $\mathbf{K}$ is the stiffness matrix of the soil-structure system - in the linear case. $\mathbf{Q}(t)$ is a source term, and is equal to the inertial force-M $1 \ddot{u}_{\mathrm{g}}(t)$ induced by the ground seismic acceleration $\ddot{\mathrm{u}}_{\mathrm{g}}$.

As Eq. 2 must be solved in a discretized domain, boundary conditions must be set at its fronteer. The use of classical boundary conditions can cause in certain situations (eg. high velocity waves, relatively small domain dimensions) the reflection of the travelling waves on the domain's borders resulting in the trapping of the waves - thus artificial oscillations - within the domain. Transmitting boundaries (i.e. viscous dampers) are well suited to overcome such phenomena, especially when solving complex soil-structure interaction problems.

\section{CASE STUDY: HIGHWAY BRIDGE}

\subsection{Bridge description}

The aforementioned methods have been applied to the seismic assessment of an existing bridge (Figure 4). It is a multi-span continuous motorway bridge located on a Swiss highway. The deck consists of six spans of: $74.15,3 \times 106.75,79.15$ and $38.45 \mathrm{~m}$ respectively, thus a total length of $512 \mathrm{~m}$. It has a variable section height, with a maximum value of $5.90 \mathrm{~m}$ at supports and a minimal value of $2.20 \mathrm{~m}$ at mid-span. It is supported by two abutments at extremities and five piers of 7, 49, 57, 22 and $11 \mathrm{~m}$, respectively. Each pier consists of a group of four columns with hollow rectangular sections, except for pier no.5 which has only 


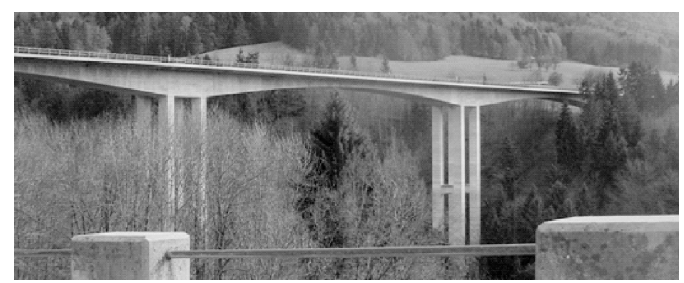

Figure 4. Bridge view.

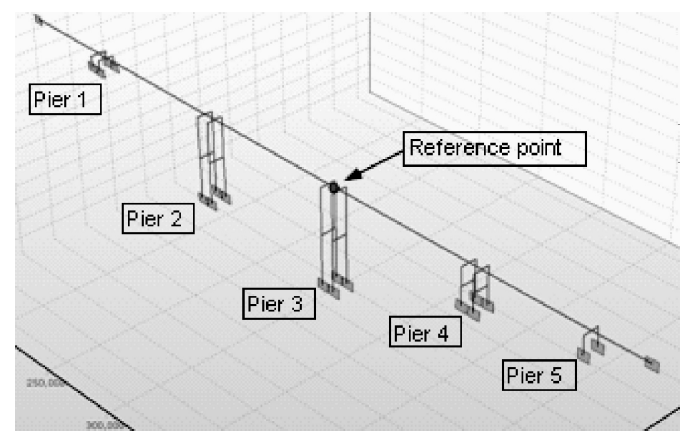

Figure 5. Simplified geometry of the bridge.

two columns with plain rectangular sections. Each column is founded on a deep cylindrical pile whose depth depends on local soil conditions.

\subsection{Numerical model}

The numerical simulations have been carried out on a simplified three-dimensional geometry of the bridge using Z_Soil (Z_Soil v7 2007) and SeismoStruct, a nonlinear finite element code dedicated to static and dynamic analyses of framed structures (SeismoSoft 2006). The deck was modelled by considering an equivalent Timoshenko beam with the same properties (area, inertia moments and torsional coefficient) as the real deck's cross section. Linear elastic behaviour was assumed, which is typical of prestressed concrete bridges under seismic action. The piers' columns where modelled with 3-D inelastic fibre beam elements (Spacone 1994) allowing an explicit consideration of the spread of inelasticity across the column's section and along its length, including the possible development of plastic hinges at the extremities.

The neutral axis of the equivalent beam representing the deck has been positioned at the height of the section's centre of gravity, $2.45 \mathrm{~m}$ above the column top, and connected to it by means of a rigid arm (see Figure 5).

\subsubsection{Boundary conditions}

Concerning boundary conditions, two options have been investigated. The first one, referred to as BC 1 , assumes all bridge columns founded on $12 \mathrm{~m}$ deep
Table 1. Maximum top longitudinal displacement.

\begin{tabular}{lll}
\hline & $\begin{array}{l}\text { BC 1 } \\
\text { (deep) }\end{array}$ & $\begin{array}{l}\text { BC 2 } \\
\text { (surface) }\end{array}$ \\
\hline Period, sec & 1.4 & 0.8 \\
Modal participation factor, $\Gamma$ & 1.06 & 1.21 \\
Spectral coefficient, Sd, \% & 7.6 & 13.0 \\
FR max. displacement (cm) & $\mathbf{5 . 0}$ & $\mathbf{2 . 2}$ \\
PO max. displacement (cm) & $\mathbf{8 . 0}$ & $\mathbf{8 . 6}$ \\
TH max. displacement (cm) & $\mathbf{4 . 4}$ & $\mathbf{6 . 2}$ \\
\hline
\end{tabular}

piles. Soil-structure interaction is considered in a simple form through boundary springs to which reasonable stiffness values are assigned. The second option, $\mathrm{BC} 2$, assumes all bridge columns fixed at their bases at surface level, neglecting therefore the flexibility of the foundations. For both options, the bridge is supported at the deck extremities by two abutments for which only vertical and transversal displacements are blocked, i.e. free rotation and longitudinal displacement.

\subsubsection{Model's parameters}

The mass of the deck was uniformly distributed on the equivalent beam. Column masses were also distributed along fibre beam elements. For the dynamic analysis, a Rayleigh damping ratio $\xi=0.05$ was defined for the deck. No additional damping was defined for the columns since it is implicitly included in fibre elements. Preliminary eigenvalue analysis was carried out to verify the correct model's assemblage and to evaluate frequencies (periods) and modal participation factors needed as input parameters for replacement forces and pushover analyses.

\subsubsection{Input motion}

The bridge is located in seismic zone 2, soil type E according to the Swiss norms (SIA 261 2003). The peak ground acceleration for this site is $0.1 \mathrm{~g}$. A spectrum-compatible accelerogram corresponding to this site has been generated and used as input motion for the dynamic analysis of the bridge in two horizontal directions: longitudinal (road axis) and transversal. The signal is applied at the piers' supports and at the abutments.

\subsection{Results}

The maximum displacements of a reference point of the deck (indicated on figure 5) were calculated using replacement forces (RF), pushover (PO) and time history $(\mathrm{TH})$ analyses. The results are summarised in Table 1 for the longitudinal direction and in Table 2 for the transversal direction.

Results are given for the case when the bridge is supported by deep piles (BC 1) and the case where the supports are assumed at the piers's bases (BC 2). 
Table 2. Maximum top transversal displacement.

\begin{tabular}{lcc}
\hline & $\begin{array}{l}\text { BC 1 } \\
\text { (deep) }\end{array}$ & \multicolumn{1}{c}{$\begin{array}{l}\text { BC 2 } \\
\text { (surface) }\end{array}$} \\
\hline Period, sec & 2.2 & 1.9 \\
Modal participation factor, $\Gamma$ & 1.33 & 1.29 \\
Spectral coefficient, Sd, \% & 4.6 & 5.6 \\
FR max. displacement $(\mathrm{cm})$ & $\mathbf{8 . 5}$ & $\mathbf{7 . 1}$ \\
PO max. displacement $(\mathrm{cm})$ & $\mathbf{1 1 . 6}$ & $\mathbf{1 0 . 0}$ \\
TH max. displacement $(\mathrm{cm})$ & $\mathbf{6 . 9}$ & $\mathbf{1 0 . 0}$ \\
\hline
\end{tabular}
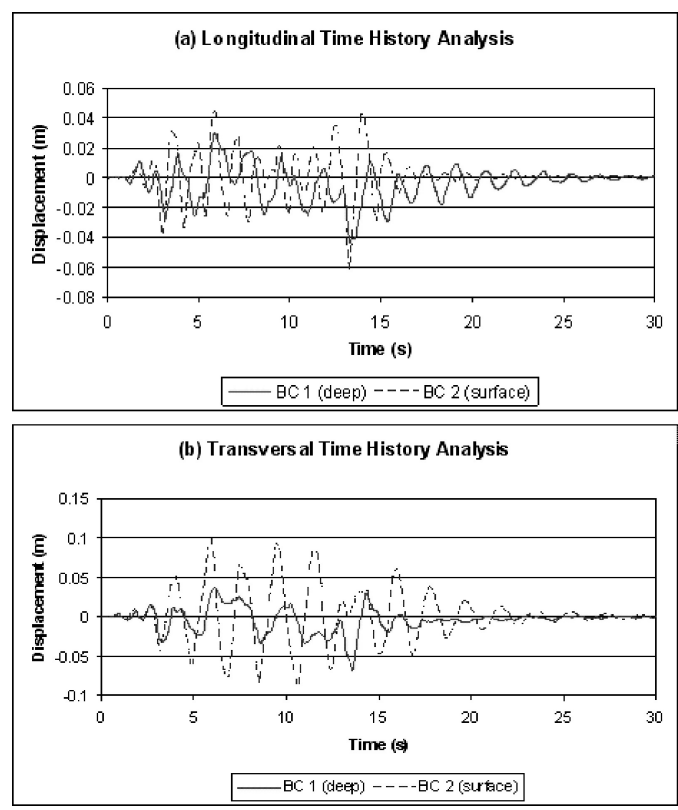

Figure 6. Time history displacement of the bridge's deck.

Globally, for a given direction, the obtained results with the three approaches are similar but no clear trend can be noticed. The time history analysis shows that the top displacements are lower for BC 1 case (deep foundation) than for $\mathrm{BC} 2$ case suggesting that the flexibility of the piles contributes to attenuate the bridge's motion (Fig. 6). This feature can not be handled by the static approaches for which no inertia effects are considered. Nevertheless, the capacity curve obtained from the PO analysis (Fig. 7) is systematically lower for the deep foundation case (BC 1) than for nearsurface foundation case $\mathrm{BC} 2$ and consequently, for a given displacement, the base shear force, which is related to the seismic action, is lower for the deep foundation case.

To assess the seismic safety of the bridge, a ratio $\alpha$ between the seismic action and the structural

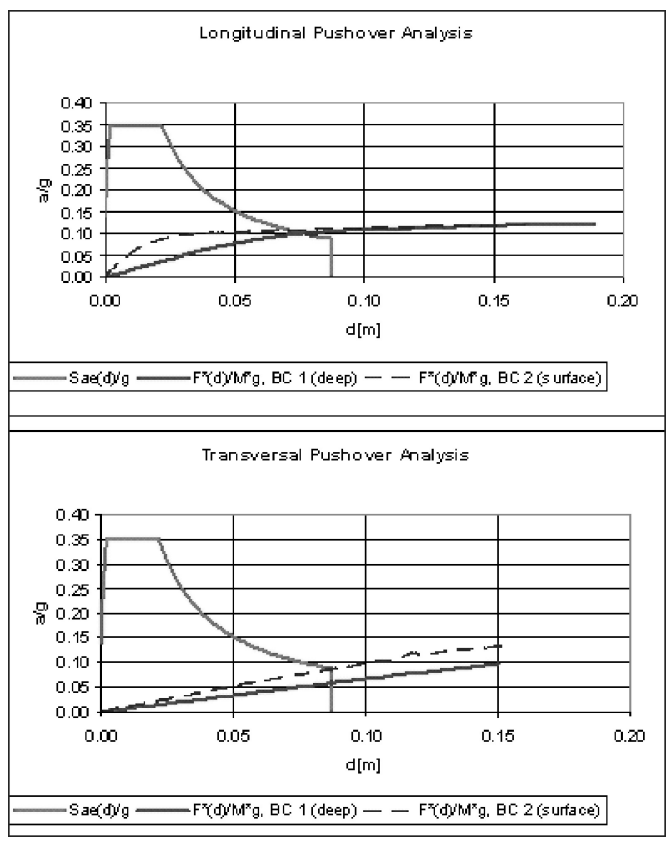

Figure 7. Pushover capacity and demand spectra.

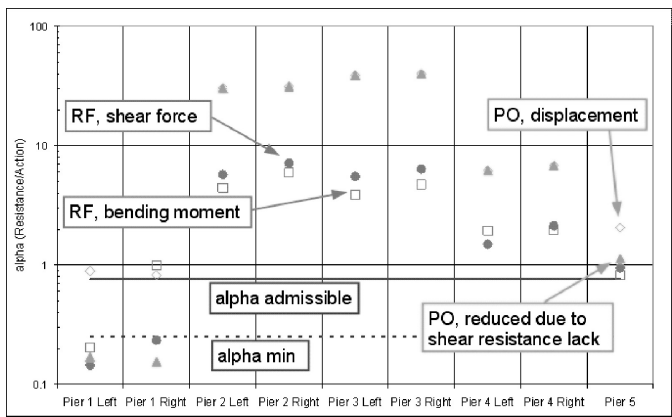

Figure 8. PO and RF alpha ratios (resistance/action) compared to Swiss norms limits (longitudinal, BC 1).

resistance - called conformity ratio - is evaluated for each pier's column. In the replacement forces approach, it is obtained from computed forces, whereas in the deformation-based approach, this ratio is obtained by dividing the column's ultimate capacity of deformation (M- $\phi$ analysis) by the corresponding calculated deformation (pushover analysis).

The obtained ratios (Fig. 8) for replacement forces and pushover analyses are compared to the Swiss norms minimal and admissible values. It is shown that PO $\alpha$-ratios are higher than RF ratios and that PO approach permits to take advantage from the flexibility of the structure to evaluate its seismic safety. 


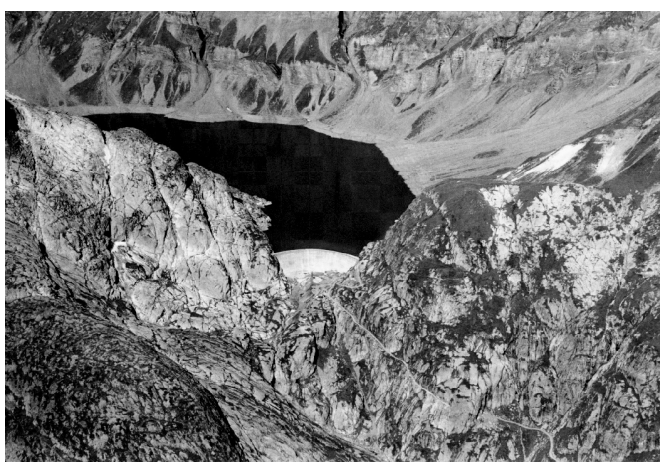

Figure 9. Dam situation.

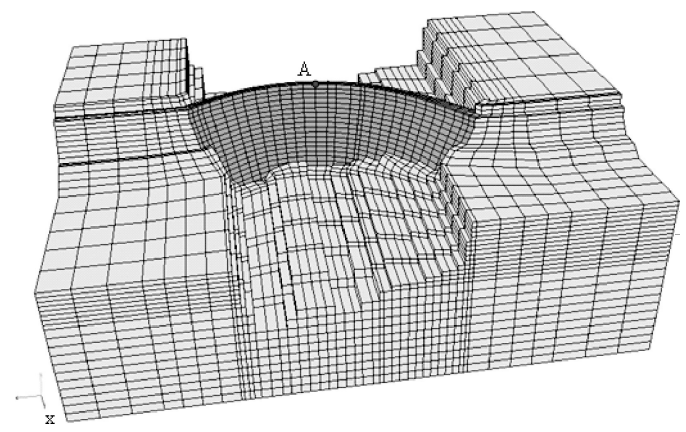

Figure 10. 3D FE model.

\section{CASE STUDY: ARCH DAM}

\subsection{Dam description}

The dam is depicted in Figure 9. It is located in the Swiss Alps, and founded on good rock, i.e. gneiss.

The FE model used within (Z_Soil v7 2007) is illustrated in Figure 10. It consists of about 17,000 volumic 8-nodes elements.

Displacement boundary conditions are fixed at a distance of about 1 to 1.5 times the height of the dam.

\subsection{Applicability of the different methods}

\subsubsection{Replacement forces method}

According to (Darbre et al. 2003) this method should only be applied to small weight dams. It should include the effect of the water reservoir, which will act as an additional mass that will oscillate with the dam. This effect can be obtained analytically, considering horizontal slices of the dam (Westergaard's formulation).

As pointed out previously, this linear method will lead to simplified results. This can be of some interest as a control for a more complex analysis, but is probably not sufficient to assess the seismic security of such an arch dam.

\subsubsection{Nonlinear pushover analysis}

To the authors' knowledge, there are no examples of pushover analysis applied to arch dams in the literature. Unlike buildings or bridges, the model of an arch dam is not easily reducible to a $1 \mathrm{DOF}$ system, and the hydrodynamic interaction (oscillating water mass) would be difficult to model as well.

\subsubsection{Dynamic time history analysis}

The only way of introducing rigourously both the structure and the underlying rock foundation in our model is to use the dynamics equations of motion (Eq. 2). The solving of the global soil-structure interaction problem, as described in (Kramer 1996), can be subdivised into two distinct steps, in the case of linear behavior:

- Kinematic interaction, i.e. the effect of the structure's foundation stiffness preventing the soil displacements due to the earthquake.

- Inertial interaction, i.e. the effect of the inertial forces in the structure.

Neglecting kinematic interaction - allowable here for a rigid soil foundation and assuming that all the points at the surface move in phase - leads to the following form of Eq. 2, in the linear case:

$$
\mathbf{M}_{t o t} \ddot{\mathbf{u}}+\mathbf{C} \dot{\mathbf{u}}+\mathbf{K}_{\text {tot }} \mathbf{u}=-\mathbf{M}_{\text {struct }} \ddot{u}_{g}(t)
$$

\subsection{Simplified time history analysis}

The soil-structure interaction problem is solved for the arch dam with a simplified, linear time history analysis, considering four models:

- Model 1: dam only, no foundation, no damping. Eq. 2 reduces to:

$$
\mathbf{M}_{\text {struct }} \ddot{\mathbf{u}}+\mathbf{K}_{\text {struct }} \mathbf{u}=-\mathbf{M}_{\text {struct }} \mathbf{1} \ddot{u}_{g}(t)
$$

- Model 2: dam only, no foundation, with damping. Eq. 2 reduces to:

$$
\mathbf{M}_{\text {struct }} \ddot{\mathbf{u}}+\mathbf{C} \dot{\mathbf{u}}+\mathbf{K}_{\text {struct }} \mathbf{u}=-\mathbf{M}_{\text {struct }} \mathbf{u}_{g}(t)
$$

- Model 3: dam with foundation (corresponds to Fig. 10 , with $\left.\gamma_{\text {rock }}=\gamma_{\text {concrete }}=24 \mathrm{kN} / \mathrm{m}^{3}\right)$, with damping. Eq. 2 holds, and can be rewritten:

$$
\mathbf{M}_{t o t} \ddot{\mathbf{u}}+\mathbf{C} \dot{\mathbf{u}}+\mathbf{K}_{t o t} \mathbf{u}=-\mathbf{M}_{t o t} \mathbf{1} \ddot{u}_{g}(t)
$$

- Model 4: dam with massless foundation (corresponds to Fig. 10, but $\gamma_{\text {rock }}=0$ ), with damping. This formulation is the one suggested by the Swiss Federal Office of Energy (Darbre et. al 2003). In this case, Eq. 2 reduces to:

$$
\mathbf{M}_{\text {struct }} \ddot{\mathbf{u}}+\mathbf{C} \dot{\mathbf{u}}+\mathbf{K}_{\text {tot }} \mathbf{u}=-\mathbf{M}_{\text {struct }} \mathbf{1} \ddot{u}_{g}(t)
$$




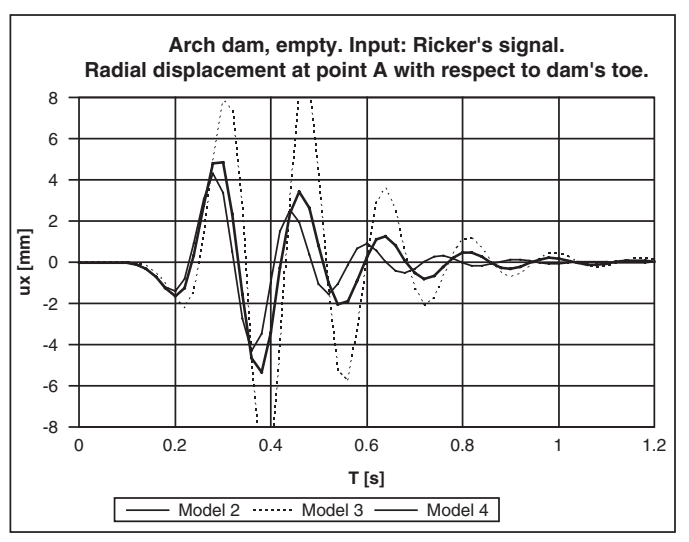

Figure 11. Displacement time history of point A.

Comparing Eq. 7 with Eq. 3, it can be noticed that inertia forces within the rock foundation are neglected in the right-hand side.

General hypotheses applied to the four models are the following:

- Linear behavior for both concrete and rock.

- Rock stiffness is taken equal to concrete stiffness. $\mathrm{E}_{\text {rock }}=E_{\text {concrete }}=26 \mathrm{GPa}$.

- When damping is present, it takes the form of Rayleigh damping of $5 \%$ on $1 \mathrm{~Hz}$ and $10 \mathrm{~Hz}$ frequencies.

- Empty lake conditions, no water oscillating mass.

- A $5 \mathrm{~Hz}$ Ricker's signal is applied to the model, in the direction $\mathrm{x}$, parallel to the river. The spatial distribution of this signal is constant.

- The size of the elements has been checked to be able to transmit the waves.

- HHT time integration algorithm with $\alpha=-0.3$.

\subsection{Results}

The radial displacement time history $\mathrm{u}_{\mathrm{x}}$ of point $\mathrm{A}$ with respect to dam's toe is illustrated in Figure 11.

Model 2 (dam without foundation) gives a slightly smaller maximal displacement with respect to Model 1 (not represented in the figure), because of the introduction of the 5\% damping. Model 4 (dam with massless foundation) and Model 2 are very close in terms of amplitude. There is a slight delay in the response of Models 3 and 4 with respect to Model 2, which may be explained by the absence of the rock foundation in the latter case.

A large amplification of the signal can be noticed for Model 3 (dam with foundation with $\gamma=25 \mathrm{kN} / \mathrm{m}^{3}$ ) with respect to Models 2 and 4, which is due to the reflection of the waves on the classical boundary conditions. In order to limit this effect in the soil-structure interaction problem, one would have to extend the domain, or use transmitting boundaries, allowing the signal to leave the domain.

\section{CONCLUSION}

It has been shown in this paper that nonlinear pushover analysis gives an efficient alternative to the commonly used linear replacement forces method for the assessment of seismic safety of bridges (and buildings). It is of particular interest for existing structures, as the gain in security can sometimes prevent a costly reinforcement.

However, for complex structures like arch dams, both pseudo-static methods show their limitations, and a dynamic time history analysis should be conducted. When the foundation is rigid enough, simplifying hypotheses allow the use of classical displacement boundary conditions to solve an approximate problem (Models 2 or 4 are applicable). Otherwise, in the presence of soft soils and/or coupling with water pressure, the full soil-structure interaction problem should be solved with the help of transmitting boundaries.

\section{ACKNOWLEDGEMENTS}

The authors would like to thank Prof. Th. Zimmermann, Swiss Federal Institute of Technology in Lausanne, for his help and advice during the computations of the presented case studies.

\section{REFERENCES}

Belgasmia M., Spacone E., Urbanski A. \& Zimmermann Th. 2006. Seismic evaluation of constructions: static pushover procedure and time history analysis for nonlinear frames. LSC internal report, Swiss Federal Institue of Technology, Lausanne

Darbre G. et al. 2003. Sécurité des ouvrages d'accumulation. Documentation de base pour la vérification des ouvrages d'accumulation aux séismes, Swiss federal office of energy

EuroCode 8 2003. Calcul des structures pour leur résistance aux séismes, comité européen de normalisation

Kramer S.L. 1996. Geotechnical earthquake engineering, Prentice Hall

SeismoSoft 2006. SeismoStruct - A computer program for static and dynamic nonlinear analysis of framed structures, www.seismosoft.com

SIA 2018 2004. Vérification de la sécurité parasismique des bâtiments existants, Swiss norms SIA Zurich

SIA 261 2003. Actions sur les structures porteuses, Swiss norms SIA Zurich

Spacone E. 1994. Flexibility-based FE Models for the Nonlinear Static and Dynamic Analysis of Concrete Frame Structures, Ph.D. dissertation, Univ. of California, Berkeley

Z_Soil v7 2007. User manual, www.zace.com, Elmepress 